\title{
MICRODISCECTOMIA LOMBAR
}

\author{
TECNICA E RESULTADOS EM 80 CASOS
}

JOSE CALASANS DOS SANTOS*, PAULO J. CARDOSO LIMA**

RESUMO - Os autores analisam seus resultados em 80 pacientes com hérnia discal lombar submetidos a microdiscectomia. Observam o baixo indice de complicaçóes pós-operatórias, o curto período de internação hospitalar e o retorno rápido dos pacientes às suas atividades laborativas.

PALAVRAS-CHAVE: hérnia discal lombar, microdiscectomia.

Lumbar microdiscectomy : technics and results in 80 cases

SUMMARY - The results of treatment for 80 patients with lumbar disc disease who undergone microdiscectomy were reviewed. Low rate of post-openative complications, short hospital stay and early return of the patients o their normal activities were observed.

KEY WORDS: Iumbar disc disease, microdiscectomy.

Schmorl foi o primeiro a descrever, em 1927, a ruptura de disco intervertebral no interior do corpo de uma das vértebras 6 . Contudo, já em 1909, Krause descrevera operação realizada em determinado paciente no qual Oppenheim havia diagnósticado uma lesão localizada em L4 5. Krause encontrou massa extradural, descrita pelo anátomo-patologista como sendo um condroma; a operação resultou em cura. Foram Mixter e Barr 4 que, em 1934, demonstraram serem estas lesões, na realidade, fragmentos de discos intervertebrais responsáveis por casos de ciática, permitindo avanços diagnósticos e terapêuticos. Naquela época os meios diagnósticos eram imprecisos e as cirurgias mutiladoras, consistindo em laminectomias totais com exploração de vários níveis em busca da protusão discal. A mortalidade era alta. em torno de $20 \% 3$. Love 2 , em 1939 , descreveu técnica para exérese do disco por meio da flavectomia (fenestração interlaminar do ligamento amarelo) associando, se necessário, hemilaminectomia, com avanço na técnica cirúrgica e diminuição da mortalidade. Em 1977, Caspar e Loew relataram técnica cirúrgica através de pequena incisão, com o auxílio de microscópio cirúrgico e instrumental especializado, iniciando a era microcirúrgica para o tra. tamento das hérnias discais 1,6. Com o desenvolvimento da microcirurgia em geral, Willams 7, em 1978, desenvolveu técnica para a operação de hérnia de disco, com poucas modificações, a qual denominou microdiscectomia, sendo então popularizada.

Deve ser explicada a etiopatogenia da hérnia do núcleo pulposo em base de pressão extraordinariamente elevada sobre o núcleo, de debilídade do anel fibroso ou de ambos os mecanismos 6. Segundo a opinião da maioria dos autores, a explicação mais realista desta protusão é a de que se produz uma série de alterações bioquímicas, em decorrência das quais o núcleo pulposo perde seu

Serviço de Neurocirurgia dos Hospitais São José e Dr. Augugto César Leite, Aracaju: *Neurocirurgião; **Médico Residente de Neurocirurgia. Aceite: 04-setembro-1992.

Dr. José Calasans dos Santos - Departamento de Neurocirurgia, Casa de Saúde de Campinas Praça Dr. Toffoli 28 - 13015-240 Campinas SP - Brasil. 
comportamento como estrutura gelatinosa e sua capacidade para distribuir uniformemente as forças, transmitindo forças elevadas a certas áreas do anel 6. Também se tem demonstrado que, a partir de alterações bioquímicas do anel fibroso, ocorrem mudanças estruturais do próprio anel, havendo lacerações e fissuras radiais com posterior migração e prolapso do núcleo. Não está totalmente esclarecida a relação entre os fatores bioquímicos e a resistência estrutural, porém tem-se demonstrado que cargas repetidas sobre o disco levam a que ele perca sua capacidade de absorver líquido (desidrate), modificando o ângulo de inserção das fibras de colágeno do anel fibroso, e que forças de torsão fisiologicamente normais podem, com esta mudança na angulação, produzir lacerações radiais 6.

Relatamos nossa experiência com a microdiscectomia em pacientes com hérnia de disco lombar.

\section{MATERIAL E MÉTODO}

Estudamos 80 pacientes com hérnia discal lombar, sendo realizado o diagnóstico por mielografia, tomografia computadorizada, tomografia associada a mielografia e ressonância nucletar magnética.

Ao final de cada ato cirúrgico foi preenchido protocolo pelo cirurgião ao qual foram anexados, posteriormente, os dados evolutivos de cada paciente. Estudamos o nível da hérnia discal lombar, o tempo operatório, o tempo de permanéncia hospitalar após o ato cirúrgico, complicações e resultados, relacionando-os com o retorno às atividades laborativas. Todos os pacientes foram acompanhados por periodo de 18 a 24 meses.

\section{RESULTADOS}

Nível das hérnias. O nível era L4-L5 em 41 pacientes $(51,2 \%)$, L5-S1 em 35 (43,7\%), La-LA em $2(2,5 \%)$, Lis-La3 em $2(2,5 \%)$.

Tempo operatório (TO). O TO médio foi 62 minutos, sendo o tempo mais rápido 35 minutos, observado em uma hérnia extrusa, e o mais demorado 130 minutos.

Tempo de permanência hospitalar (TPH). O TPH médio foi 72 horas.

Complicações. Ocorreu deiscência parcial de sutura em 2 pacientes $(2,5 \%) ; o s ~ 2$ pacientes eram idosos e a cirurgia se prolongou por mais de 120 minutos, o que pode ser explicado por levar o afastador de Caspar a isquemia das bordas da pele com o aumento do tempo cirúrgico; a partir daí passamos a evitar a isquemia, diminuindo a tensão do afastador ou aumentando a incisão. Tromboflebite de membros inferiores foi observada em 1 paciente $(1,2 \%)$ com antecedentes de varizes. Fibrose perirradicular foi observada em 1 paciente (1,2\%), que apresentou sintomatologia após 12 meses da operacão.

Foraminotomia. Em 10 pacientes $(12,5 \%)$, além da exérese do disco herniado, realizamos fonaminotomia, mais frequentemente nos pacientes acima de $\mathbf{5 0}$ anos.

Resultados: (a) Faixa etária 55-68 anos: 12 pacientes (15\%): - Exame neurológico normal, 10 pacientes $(12,5 \%)$; retorno às atividades laborativas, - Lombalgia, 2 pacientes (2,5\%): realizaram fisioterapia com melhora, retornando às suas atividades laborativas. (b) Faixa etária 19-54 anos, 68 pacientes $(85 \%)$ : - Exame neurológico normal, 66 pacientes (82,5\%); retorno às atividades laborativas, porém 6 pacientes retornaram em atividades mais leves por serem idosos e carregadores de peso. - Sem melhora após cirurgia, 2 pacientes (2,5\%); realizamos revisão neurorradiológica: em 1 paciente houve erro de espaço e o outro desenvolveu fibrose perirradicular com melhora após reoperação.

\section{COMENTARIOS}

Técnica cirúrgica. Os pacientes são submetidos a anestesia geral e colocados na posição proposta por Tarlov (genu-peitoral) pois, nesta posição (Fig. 1) existe maior flacidez abdominal, sendo o volume de sangramento mínimo, e maior hiperflexão da coluna com maior abertura do espaço intervertebral. Em decúbito lateral observa-se maior sangramento intraoperatório, aumentando 0 tempo cirúrgico e somente adotamos esta posição em pacientes com patologias 
que inviabilizem a posição de Tarlov, como também em pacientes obesos. A incisão da pele é pequena, de 2,5 a $3,0 \mathrm{~cm}$ (Fig. 1). No caso do espaço $L 5-\$ 1$ a incisão é feita tomando por base a borda superior da apofise espinhosa de L5 e a borda superior da apofise espinhosa de $\mathbf{S 1}$, sendo este espaço praticamente retilíneo. Nos espaços acima de L5-S1 observamos a necessidade de ultrapassar de 0,3 a $0,5 \mathrm{~cm}$ a borda superior da vértebra suprajacente.
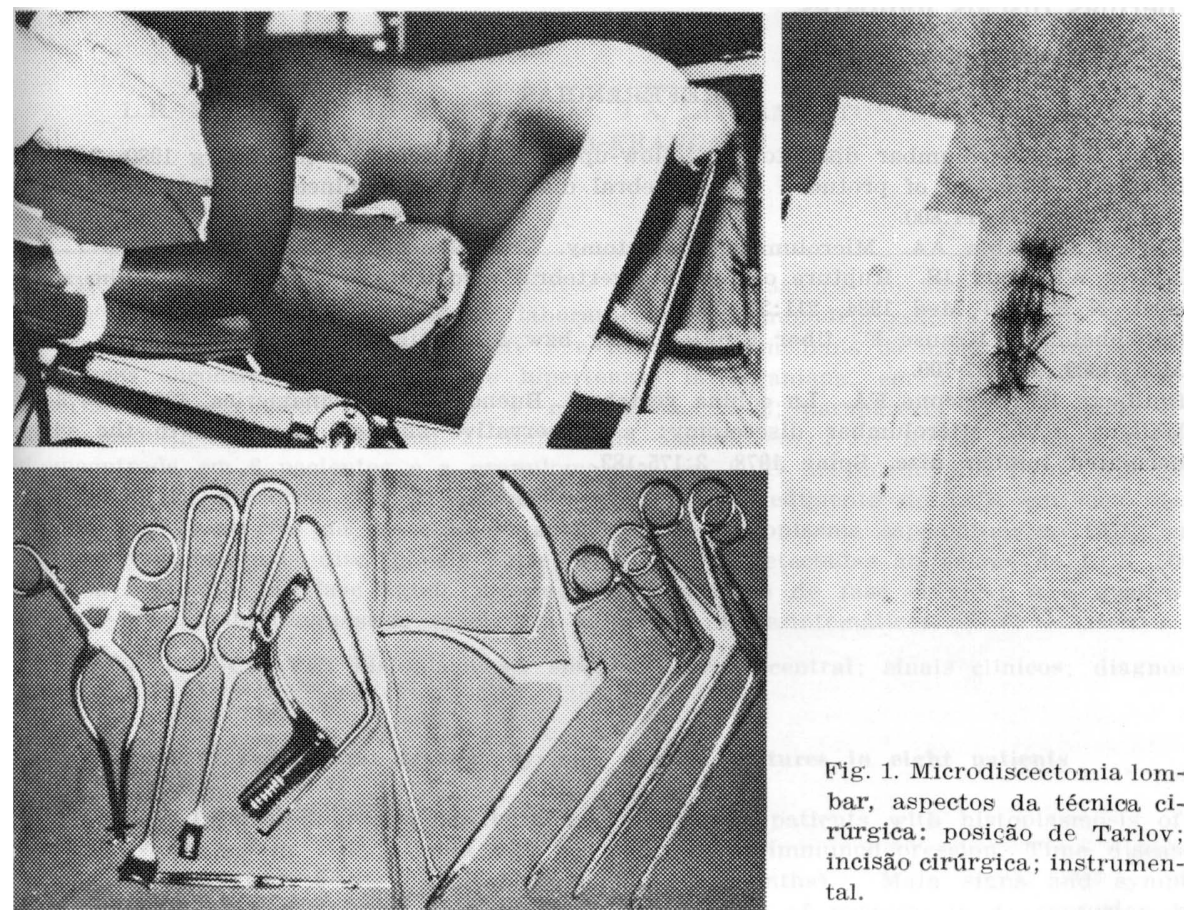

Fig. 1. Microdiscectomia lombar, aspectos da técnicia cirúrgica: posição de Tarlov; incisão cirúrgica; instrumental.

Após a incisão da pele é realizada incisão em meia-lua da fascia tóracolombar com bisturi comum; tomando por base os limites superior e inferior da incisão da pele, sua borda lateral é defletida medialmente. Por meio de rugina é feito divulsionamento dos feixes musculares e coloca-se retrator de Langenbeck e, seguidamente, afastador de Caspar. Com o auxílio do microscópio cirúrgico, em aumentos de $10 \mathrm{x}$ e $16 \mathrm{x}$ é realizada a ligamentectomia associando, se necessário, a hemilaminectomia, fato este mais comum nos espaços acima de L5-S1. Visualizada a raiz, ela é afastada com Scoville. Após afastá-la, existe pequeno sangramento dos vasos peridurais. Realiza-se hemostasia com pinça bipolar e procura-se a hérnia discal. Após visualizada, abre-se o ligamento longitudinal posterior com microbisturi e, com pinças Love reta e angulada, é retirado o disco herniado. As hérnias discais extrusas podem ser operadas por esta técnica, pois a ampliação do campo cirúrgico, se necessária, pode ser realizada e o afastador de Caspar permite um campo de profundidade de aproximadamente $5 \mathrm{~cm}$, - que equivale à exploração de dois espaços. Não realizamos a curetagem e só realizamos a foraminotomia se após a exérese do disco herniado, ao afastarmos a raiz, notarmos pouca mobilidade, principalmente no segmento distal (forame de conjugação). Este fato é mais comum em pacientes idosos. Envolvemos a raiz com gordura peridural, técnica proposta por Langenskiolo e Kiviluoto para evitar aderências 6 . A sintese é realizada por planos.

Avaliação da técnica. Este tipo de técnica reduz a chance de laceraçōes da dura-máter, traumatismo da raiz e lesão de grandes vasos, porque o cirurgião tem melhor visão do campo e pode entrar diretamente no espaço intervertebral. A hemostasia torna-se fácil, diminuindo os riscos de hematomas ou aderências. 
O TO é reduzido em torno de 62 minutos e o TPH, em torno de 72 horas. As complicações são raras e o retorno às atividades de trabalho é rápido, em torno de 30 dias.

Devido à facilidade de visualização do campo cirúrgico com segurança, baixo índice de complicações, curto período de internamento hospitalar e retorno rápido às atividades de trabalho, adotamos como rotina a técnica microcirúrgica nas hérnias discais lombares.

\section{REFERENCIAS}

1. Goald HJ. Microlumbar discectomy: follow-up of 477 patients. J Microsurg 1980, 2:95-100.

2. Love JG. Removal of protuded intervertebral disks without laminectomy. Proc. Staff Meet Mayo Clin 1939, 14:800.

3. Maroon JC, Ab'a AA. Microlumbar discectomy. Clin Neurosurg 1985, 33:407-417.

4. Mixter WS, Barr IS. Rupture of the intervertebral disc without involvement of the spinal cord. N Engl J Med 1934, $211: 210-215$.

5. Oppenheim H, Krause F. Uber Einklemmung bzw Strangulation der Cauda equina. Dtsch Med 1909, 35:697-700.

6. Rothman RS, Simeone FA. La coluna vertebral. Buenos Aires: Panamerica, 1985, p 476-662.

7. Willams RW. Microlumbar discectomy: a conservative surgical approach to the virgin herniated lumbar disc. Spine 1978, 3:175-182. 